\title{
MÉTODOS DRAMÁTICOS APLICADOS A INTERVENÇÕES SOCIOEDUCATIVAS DE AUTOGESTÃO E CONTABILIDADE
}

\author{
DRAMATIC METHODS APPLIED TO SOCIO-EDUCACIONAL \\ INTERVENTIONS REGARDING SELF-MANAGEMENT AND ACCOUNTING.
}

\section{MÉTODOS DRAMÁTICOS APLICADOS A INTERVENCIONES SOCIO- EDUCATIVAS DE AUTOGESTIÓN Y CONTABILIDAD.}

\author{
DOUGLAS TAVARES BORGES LEAL \\ Bacharel em Ciências Contábeis pela FEA/USP, \\ Mestrando em Controladoria e Contabilidade pela FEA/USP e Graduando em Licenciatura \\ em Artes Cênicas pela ECAUUSP. Professor Auxiliar do Centro Universitário Álvares Penteado \\ (FECAP) e Pesquisador da FIPECAFI. \\ dodi@usp.br
}

\begin{abstract}
SILVIA PEREIRA DE CASTRO CASA NOVA
Bacharel em Administração Pública (EAESP/FGV);

Mestre e Doutora em Controladoria e Contabilidade (FEA/USP); Pós-Doutora (EAESP/FGV).

Professora do Departamento de Contabilidade e Atuária da FEA/USP

silvanova@usp.br

Artigo originalmente apresentado no $7^{\circ}$ Congresso USP de Controladoria e Contabilidade, São Paulo/SP, 26 e 27 de julho de 2007.
\end{abstract}

\section{RESUMO}

O objetivo da pesquisa é verificar quais as contribuições que o uso de técnicas dramáticas pode proporcionar no âmbito de intervenções socioeducativas de Autogestão (gestão democrática) e de Contabilidade no contexto da educação não formal. Inicialmente, apresenta-se um estudo teórico sobre dois métodos dramáticos comumente utilizados em práticas educativas. O primeiro deles é o Role-Playing (RP), de vivência de papéis, o qual já se aplica 
no Ensino Superior de Contabilidade. Outro método discutido é o Teatro do Oprimido (TO), criado e desenvolvido pelo reconhecido teatrólogo Augusto Boal. Como meio de estudar as vantagens da utilização destes métodos de dramatização no ensino da Contabilidade, empreendeu-se uma oficina experimental na Incubadora Tecnológica de Cooperativas Populares da Universidade de São Paulo (ITCP-USP), instituição atuante no movimento de Economia Solidária (ES). Verificou-se, com a pesquisa, a eficácia dos métodos de dramatização utilizados para vivência e compreensão dos processos relacionados à gestão. A experiência com o TO e o RP proporcionou reflexão coletiva acerca dos papéis assumidos em uma organização e evidenciou o caráter técnico do conhecimento contábil percebido pelos participantes.

Palavras-chave: Educação da Contabilidade; Role-Playing; Teatro do Oprimido.

\section{ABSTRACT}

The objective of the research is to find out what contributions that the use of dramatic techniques can provide within socio-educational interventions of Democratic Management and Accounting in the context of non-formal education. Initially, it presents a theoretical study on two dramatic methods commonly used in educational practices. The first one is the Role-Playing (PR), which already is applied in Higher Accounting Education. Another method discussed is the Theatre of the Oppressed (TO), designed and developed by the recognized theater studious Augusto Boal. As a way of studying the benefits of the use of these methods of drama in the teaching of Accounting, were made an experimental workshop in Technology Incubator of Popular Cooperatives at the University of São Paulo (ITCP-USP), active institution in the movement of Solidary Economics (ES). It was found with the search the effectiveness of the methods of drama used to experience and understanding of processes related to the management. Experience with the TO and RP provided collective reflection on the roles made in an organization and showed the technical character of the accounting knowledge perceived by the participants.

Key-words: Accounting Education; Role-Playing; Theatre of the Oppressed.

\section{RESUMEN}

El objetivo de la pesquisa es verificar cuales son las contribuciones que el uso de técnicas dramáticas pueden proporcionar en el ámbito de intervenciones socio-educativas de Autogestión (gestión democrática) y de Contabilidad en el contexto de la educación no formal. Inicialmente, se presenta un estudio teórico sobre dos métodos dramáticos comúnmente utilizados en prácticas educativas. El primero de ellos es el Role-Playing (RP), de vivencia de papeles, el cual ya se aplica en la Enseñanza Superior de Contabilidad. Otro 
método discutido es el Teatro del Oprimido (TO), creado y desarrollado por el reconocido dramaturgo Augusto Boal. Como medio de estudiar las ventajas de la utilización de estos métodos de dramatización en la enseñanza de la Contabilidad, se emprendió un taller experimental en la Incubadora Tecnológica de Cooperativas Populares de la Universidad de Sao Paulo (ITCP-Usp), institución actuante en el movimiento de Economía Solidaria (Es). Se verificó con la pesquisa la eficacia de los métodos de dramatización utilizados para vivencia y comprensión de los procesos relacionados a la gestión. La experiencia con el TO y el RP proporcionó ponderación colectiva acerca de los papeles asumidos en una organización y evidenció el carácter técnico del conocimiento contable percibido por los participantes.

Palabras-clave: Educación de la Contabilidad; Ruede-Playing; Teatro del Oprimido.

\section{INTRODUÇÃO}

\subsection{Contextualização}

Observa-se, nos recentes estudos da Educação da Contabilidade para o ensino superior, que os métodos tradicionais de ensino, nos quais o educando tem um papel passivo, estão dando espaço para outros que proporcionam aos alunos o desenvolvimento de competências e posturas inovadoras (PELEIAS, 2006). Essas competências, estimuladas pelo ensino relacionadas à criatividade, improvisação, flexibilidade e percepção subjetiva (RUAS, 2004), contribuem na formação humana dos educandos, agentes políticos da nossa sociedade.

A técnica de ensino do Role-Playing (RP), ou do jogo de papéis, é um exercício didático de alteridade social. Ao se colocarem no papel do outro, os educandos brincam com suas habilidades para que possam refletir coletivamente sobre as situações envolvidas na "brincadeira". O método do RP, muito utilizado em cursos superiores das áreas de Administração e Contabilidade nos Estados Unidos (HASKINS e CRUM, 1985; CRUMBLEY, SMITH e SMITH, 1998), na Austrália e no Canadá (CRAIG e AMERNIC, 1994), ainda não é muito conhecido no Brasil. Apesar de empresas multinacionais terem aderido ao RP na capacitação e treinamento de seus funcionários, e até mesmo em seus processos de seleção de pessoas, este método ainda não é muito difundido nos países latinos. Além disso, são poucos os trabalhos científicos das áreas da Gestão que o estudam (CARVALHO e CARVALHO, 2004).

Além do RP, outros métodos dramáticos vêm sendo aplicados em intervenções socioeducativas. A proposta do Teatro do Oprimido (TO), muito difundida e reconhecida na maior parte dos países da América Latina, da América do Norte e da Europa (CARVALHO e CARVALHO, 2004), é de origem brasileira e foi criada por Augusto Boal, um dos mais importantes representantes mundiais das Artes Cênicas do último século, que, aos 75 anos de idade, continua envolvido com o teatro político no Centro de Teatro do Oprimido (CTO), no Rio de Janeiro. O conjunto de técnicas relacionadas ao TO constitui ferramenta político- 
pedagógica de intervenção que possibilita a compreensão das relações de opressão vividas pelos sujeitos em sociedade. Por meio da proposição de conflitos e da demarcação dos personagens envolvidos, os indivíduos que "brincam" de TO participam de um jogo teatral de criação e debate de cenas. Dessa forma, o diálogo cênico dos conflitos sociais (representados pela imagem, pelo som e pela palavra) estimula os sujeitos a ousarem solucionar as situações de opressão embutidas nas questões em debate (BOAL, 2005a).

Neste estudo procurou-se compreender, por um lado, aspectos relacionados à percepção sobre a autogestão (gestão democrática) e a contabilidade de atuantes do movimento da Economia Solidária (ES) e, por outro lado, perceber-se o grau em que as técnicas de dramatização aqui sugeridas favorecem a intervenção pedagógica no grupo pesquisado.

\subsection{Objetivo}

O objetivo principal deste trabalho foi verificar empiricamente quais as contribuições que o uso de técnicas dramáticas (RP e TO) pode proporcionar no âmbito do ensino e da vivência prática da Contabilidade de pessoas envolvidas no chamado movimento de Economia Solidária. Além disso, procurou-se observar se a união do RP ao TO contribui para uma abordagem "viva" e crítica de temas relacionados à Contabilidade e Autogestão. Paralelamente, como objetivo secundário, pretendeu-se também verificar qual o papel que assume a Contabilidade e a Gestão perante os sujeitos, no contexto opressor-oprimido.

Para a consecução dos objetivos, foi feito um estudo empírico de intervenção com membros da Incubadora Tecnológica de Cooperativas Populares da Universidade de São Paulo (ITCP-USP), que são formadores do projeto, ou seja, apoiam a formação e o acompanhamento de empreendimentos solidários. A dinâmica se desenvolveu por meio de uma oficina dramática, tendo como objetivo proporcionar uma reflexão acerca dos papéis e posturas assumidas pelos formadores nas diversas situações do dia-a-dia de seu trabalho.

A adoção do método do RP teve como intenção proporcionar subsídios para que se avaliasse a efetividade de técnicas de ensino nas quais os sujeitos têm um papel ativo. Os princípios e os exercícios providos do TO de Boal (2005b) foram usados na execução da intervenção no grupo para fortalecer a caracterização dos papéis (oprimido e opressor) e para considerar as relações sociais em um contexto mais amplo de poder.

\section{REFERENCIAL TEÓRICO}

\subsection{Técnicas de Ensino da Contabilidade}

Métodos que possibilitem a autonomia do estudante perante o conhecimento e, consequentemente à vida social e política, são bem-vindos à educação (FREIRE, 2001). Segundo Nérici (1989), deve ser objetivo de qualquer método ou técnica didática tornar o educando independente do educador, de modo que ele possa orientar a si mesmo em estudos futuros e na sua participação na sociedade. 
Para que haja a formação crítica dos estudantes é fundamental uma comunicação dialética entre educador-educando (FREIRE, 2001). De acordo com este autor, se não há diálogo, ou seja, se entre duas partes uma prepondera, não há uma comunicação verdadeira. A educação, por sua vez, não existe na ausência de comunicação.

Poucas são, além da aula expositiva, as técnicas utilizadas no ensino da Contabilidade. Entretanto, métodos que promovam a interação em grupos e a descoberta pelos estudantes como, por exemplo, os jogos de empresas e os projetos de pesquisa ajudam a afastar os alunos da artificialidade da educação tradicional (PELEIAS, 2006). O envolvimento ativo dos educandos com o mundo real é também apontado por Marion (2001) no que se refere a simulações e jogos de empresas desenvolvidos por meio de "softwares educacionais" que permitem diversas opções dos alunos, que podem revisar constantemente suas decisões.

\subsection{Role-Playing (RP) e a proposta didática de vivência de papéis}

O método do Role-Playing, concebido inicialmente pelo psicólogo social Jacob Levy Moreno no início do século XX, é uma variante do psicodrama, que pode ser usado para fins terapêuticos e/ou educativos. No âmbito da educação, o RP traz à tona questões construídas nas relações pessoais e valoriza a dinâmica dos grupos ao valorizar o jogo e privilegiar o lúdico (CARVALHO e CARVALHO, 2004).

Uma intervenção pedagógica que faz uso do RP é realizada por meio da vivência de papéis pelos estudantes, associada a determinado conflito que se queira trabalhar. Os estudos que tratam do desenvolvimento do método Role-Playing (KRASILCHIK, 1996; NÉRICI, 1989;

SWINK, 1993) sugerem o desenrolar da intervenção em basicamente três etapas:

- Preparo: os estudantes devem se preocupar antes de tudo em entender bem o conflito, as personagens envolvidas, o momento histórico e o cenário que será representado. Depois que os personagens forem distribuídos, os alunos devem estudar os argumentos de defesa dos papéis a eles incumbidos, mesmo que as opiniões destes sejam diferentes do estudante-ator.

- Representação: nesta etapa, os alunos desempenharão os seus papéis, por meio de uma mediação que permita o debate de ideias de cada um dos personagens (representados por um estudante ou um grupo de estudantes). Uma estratégia adicional é a mudança de papéis. O mediador pode pedir na primeira fase que os estudantes se preparem para desempenhar um papel, mas, na hora da representação, mudar os personagens. Essa troca contribui para que se percebam mais improvisos pelos atores, mas só será possível se estes tiverem estudado também os outros personagens que não lhes foram incumbidos inicialmente.

- Discussão / Avaliação: em determinado momento da representação, o mediador pode permitir que os estudantes-atores deixem de lado os papéis que lhe foram atribuídos na segunda etapa e coloquem suas opiniões pessoais sobre 
os conflitos. Por fim, os atores falarão sobre o que sentiram ao desempenhar os papéis; se eles eram muito diferentes de seus valores pessoais; quais as dificuldades enfrentadas; e se houve alguma mudança de percepção do conflito.

Alguns trabalhos tratam da aplicação do RP no ensino superior de Contabilidade em países desenvolvidos. De acordo com Hayes e Reynolds (2005), o uso do método do role-playing apresenta uma série de vantagens no treinamento de estudantes que nunca tiveram uma experiência prática com negócios. Além de motivar o interesse dos educandos ao envolvê-los em atividades que desempenharão futuramente, este método proporciona um rápido feedback das decisões tomadas. Assim, o retorno imediato das ações na simulação permite que os estudantes avaliem suas decisões e desdobramentos, sem que tais ações tenham impacto no mundo real. A simulação é, então, uma forma de aprendizado que funciona como um laboratório, onde as interações e os conflitos do mundo real são antecipados àqueles que irão atuar no mundo dos negócios futuramente.

Os estudantes de Contabilidade submetidos ao role-playing, ao adotarem papéis e os desempenharem de acordo com a realidade, tornam-se mais sensíveis a outras perspectivas; são forçados a responder aos dilemas éticos relacionados à gestão; e aprendem a conhecer melhor seus pontos fortes e fracos, além de suas opiniões (CRAIG e AMERNIC, 1994.). Os mesmos autores defendem que a resolução em si dos conflitos entre os indivíduos e representantes da sociedade e das organizações é algo secundário e que todos deveriam ser considerados vencedores do jogo.

Haskins e Crum (1985) descrevem uma aplicação simples de RP (baseada em um caso real) em uma turma de Contabilidade de Custos. A proposta do exercício foi perceber quais e como seriam escolhidos os quatro critérios de alocação de custos (todos eles apresentavam problemas conceituais). Durante o desenrolar da simulação, os estudantes foram estimulados a escolher determinado critério em detrimento dos outros e a defendêlo. Isso demonstrou, em primeiro lugar, a tendência de escolha dos critérios com base em interesses individuais (já que cada grupo defendeu um gerente que era beneficiado por determinado critério) e, por outro lado, o alto grau de aderência dos estudantes aos critérios, com base em argumentos com problemas conceituais.

Além de sua aplicação em sala de aula, o RP também tem sido usado em processos seletivos e em treinamento de pessoal. Swink (1993) defende que os gerentes podem saber perfeitamente as teorias da administração de conflitos, porém, muitas vezes, Ihes falta uma prática em situações de conflito (principalmente se são trainees). De acordo com o autor, os gerentes precisam saber lidar com clientes nervosos; resolver disputas quando o clima está tenso e as emoções estão "à flor da pele"; relacionar-se com pessoas com temperamento difícil; e até mesmo lidar com o ego das pessoas quando for preciso. Não há teoria que faça com que o gerente desenvolva essas habilidades sem que haja uma vivência de conflitos. 
Essa experiência possibilita não só um melhor preparo do gerente para lidar com pessoas "temperamentais", mas também o reconhecimento pelos gerentes dos próprios limites e características comportamentais.

Todavia, o uso do RP em treinamento empresarial tem sido criticado por desvirtuar a intenção inicial do psicodrama de Moreno, que propunha o desenvolvimento da espontaneidade e da recriação de papéis. Naffah (1979) chama essa aplicação do RP de role-training e julga que seu uso pelas empresas acaba reforçando os papéis já existentes, determinando, assim, o comportamento dos indivíduos em benefício da preservação das instituições e do sistema econômico-político-simbólico vigente.

\subsection{O Teatro do Oprimido (TO) e as relações oprimido-opressor}

Augusto Boal é o responsável pela proposição de diversas técnicas dramáticas que marcaram o teatro político nas últimas cinco décadas. Natural do Rio de Janeiro (1931), Boal estudou na School of Dramatics Arts da Universidade de Columbia, nos Estados Unidos, onde foi aluno do dramaturgo John Gassner. Em 1956, já de volta ao Brasil, Boal dirigiu o Teatro de Arena de São Paulo. Entre 1971 e 1986, ficou exilado do Brasil por conta da ditadura militar. Nos países em que morou nesse período (Argentina, Portugal, França e Inglaterra), desenvolveu diversas experiências teatrais por meio das quais obteve reconhecimento do público, da crítica e dos estudiosos do meio teatral. De volta ao Brasil, em 1986, fundou o Centro de Teatro do Oprimido (CTO) no Rio de Janeiro. Atuou em diversos presídios do País e ainda foi vereador da Cidade do Rio de Janeiro, de 1992 a 1996. Devido à grande contribuição de suas técnicas teatrais para a compreensão e a busca por soluções aos problemas em comunidade, em 2003 o prefeito da Cidade de Nova lorque (EUA) proclamou que o dia 27 de maio passaria a ser o Dia do Teatro do Oprimido.

Inspirado no movimento político pelo qual o Brasil passava nos anos 60 e 80, e também em expoentes do teatro político, como Bertolt Brecht, Boal desenvolve um empreendimento político-cultural que se vale de técnicas teatrais para favorecer a compreensão e a busca de alternativas para problemas pessoais e comunitários (CARVALHO e CARVALHO, 2004).

De acordo com Teixeira (2005), nem sempre os canais formais de participação social são suficientes para detectar as demandas da população, sendo então necessária a busca pela participação popular por meio de novas linguagens. As técnicas teatrais criadas por Augusto Boal atuam no sentido de aproximar as pessoas da política e a política das pessoas. As mais importantes técnicas de Boal são o Teatro Imagem, Teatro Jornal, Teatro Fórum, Arco-Íris do Desejo, Teatro Legislativo, Teatro Invisível e Ações Diretas (BOAL, 1996; BOAL, 2005a; TEIXEIRA, 2005).

O Teatro do Oprimido procura, através da prática de jogos, exercícios e técnicas teatrais, estimular a discussão e a problematização de questões do cotidiano, com o objetivo de oferecer uma maior reflexão das relações de poder, por meio da exploração de histórias 
entre opressores e oprimidos (TEIXEIRA, 2005). Em uma intervenção de TO, os textos são construídos coletivamente a partir das histórias de vida dos atores e do público: cria-se uma dramaturgia que emerge de experiências e problemas típicos da coletividade, como a discriminação, o preconceito, o trabalho, etc. Nas encenações teatrais, são incentivadas a ridicularização do poder, a inversão da hierarquia, a violação do decoro e a ruptura com as normas impostas pelo dominador (CARVALHO e CARVALHO, 2005).

Boal (2005a) entende que os papéis dos oprimidos e opressores não devem ser tão ingenuamente compreendidos como os bons e os maus, respectivamente. Na verdade as relações de opressão se mostram muito complexas tanto no subjetivo do homem quanto no que diz respeito ao ambiente social. Muitas vezes, um sujeito oprimido em uma situação pode ser opressor em outra e vice-versa. A proposta do TO não é simplesmente taxar os opressores e lutar contra eles, mas, sim, prover um espaço de debate com seres humanos que vivem situações de opressão todos os dias para que estes possam compreendê-las e reagir de formas diferentes perante elas.

Ao aproximar público e atores em uma reflexão conjunta sobre a opressão, o TO assume seu papel pedagógico de estímulo à participação e diálogo político (BOAL, 1996). Portanto, o Teatro do Oprimido e o conjunto de técnicas às quais está relacionado, são empregados como métodos de educação popular que contribuem para a compreensão dos indivíduos, contextualização dos fatos sociais e mudanças políticas (TEIXEIRA, 2005).

Assim como o método RP, o TO de Boal propõe uma vivência de papéis em conflito. Porém, enquanto no primeiro estimula-se a encenação de conflitos entre os papéis apenas para que haja motivação no envolvimento dos participantes (CARVALHO \& CARVALHO, 2004), no segundo considera-se que o conflito (ou a opressão) esteja relacionado à estrutura da sociedade, baseada no poder, e a sua encenação deve proporcionar uma reflexão coletiva acerca de suas características e incentivar sua superação pelos participantes.

Dessa forma, considera-se que o TO complementa o RP na medida em que, além de preservar os estímulos do RP à experimentação de papéis e à interação entre os participantes, o TO acrescenta a este método aspectos sociopolíticos dos conflitos para que os sujeitos sejam capazes de solucioná-los coletivamente.

\section{ESTUDO DE CASO}

\subsection{Metodologia}

A pesquisa se fundamentou em dois mecanismos metodológicos básicos:

- Pesquisa bibliográfica: revisão de documentos impressos pertinentes às áreas que se relacionam com o objeto deste estudo; e

- Observação Participante: observação direta intensiva de fenômenos e pessoas que configuram a representação prática do tema-objeto da pesquisa. 
De acordo com Marconi e Lakatos (2003), o método da observação participante consiste no envolvimento do pesquisador com o grupo estudado, quer seja porque pertence à comunidade e participa de suas atividades normais, ou porque se integrou a ela para obter informações.

A investigação apoia-se em um estudo de caso sobre a Incubadora Tecnológica de Cooperativas Populares da Universidade de São Paulo (ITCP-USP). O método do estudo de caso, segundo Marconi e Lakatos (2003), permite que haja a descrição de um fenômeno ou situação, mediante um estudo realizado em determinado espaço-tempo. Dessa forma, um caso estudado em profundidade contribui para a compreensão de casos similares.

Por meio do estudo de caso na ITCP-USP, apoiado pelo método da observação participante, buscou-se perceber quais as contribuições do uso de técnicas dramáticas de ensino na formação em Contabilidade e Autogestão. Assim, foi realizada uma intervenção socioeducativa, conduzida pelo pesquisador, que teve as seguintes características:

- Objetivos da oficina: (i) propiciar uma oportunidade de vivência prática dos conceitos de RP e TO; (ii) verificar a validade do uso conjunto desses métodos no escopo da Contabilidade e Autogestão aplicadas à Economia Solidária; (iii) verificar a efetividade desses métodos no que diz respeito aos aspectos comportamentais e de mudança de postura; e (iv) avaliar o grau de compatibilidade do uso das duas técnicas dramáticas (RP e TO).

- Público-alvo: formadores da ITCP-USP, que são estudantes universitários bolsistas provenientes de diversos cursos (Economia, Psicologia, Ciências Sociais, Biologia, etc.). Por acompanharem empreendimentos que também praticam a gestão democrática, sejam eles informais, em vias de formalização legal, ou formais, constituídos como cooperativas, os formadores da ITCP-USP podem exercer o papel de agentes multiplicadores das novas habilidades e reflexões desenvolvidas pela oficina aos grupos incubados.

- Duração da oficina: a intervenção teve a duração aproximada de quatro horas e foi realizada no mês de outubro de 2006 , em uma sexta-feira, no período da tarde, horário em que os formadores já se encontram para reuniões de formação e conselho de gestão da Incubadora.

As fontes de análise da intervenção constituem-se em registros escrito e visual. Além de um questionário de avaliação entregue aos participantes no final da oficina, baseou-se a observação dos resultados em vídeo com gravação (pela mídia DVD) dos principais momentos da oficina. Procede-se, então, a uma avaliação qualitativa sobre os eventos observados e registrados nos materiais, além de tabulação das respostas do questionário. 


\section{repec}

\subsection{Características do grupo e motivação da intervenção}

A Incubadora Tecnológica de Cooperativas Populares da Universidade de São Paulo tem como propósito apoiar a criação e a manutenção de grupos de empreendimentos populares que sejam autogestionários, ou seja, onde a gestão do negócio é feita coletivamente.

Durante o período da pesquisa, trabalhavam no projeto por volta de 30 alunos de diversos cursos da USP. O organograma da ITCP-USP tem no seu mais alto nível hierárquico o conjunto desses estudantes, que, na figura do Conselho Orientador, tomam as decisões do projeto. Abaixo desse coletivo, há a Coordenação, que é composta por duas coordenadoras e por volta de sete representantes de outros grupos de trabalho. Esses grupos de trabalho, por sua vez, encontramse abaixo da Coordenação e se dividem em Núcleos e Grupo de Ensino, Pesquisa e Extensão Multidisciplinar (Gepems). Sendo assim, resume-se a estrutura administrativa do projeto de acordo com a seguinte ordem decrescente de hierarquia e respectivo nível de participação dos formadores: (1) Conselho Orientador - espaço coletivo; (2) Coordenação - espaço representativo; e (3) Núcleos e Gepems - espaços de trabalho, onde o coletivo é fragmentado.

Para subsidiar o trabalho de formação dos grupos acompanhados, a ITCP promove, primordialmente, a formação de seus formadores. Entre as áreas envolvidas na formação dos membros dos empreendimentos e dos formadores, encontra-se a Contabilidade, que conta com especial atenção, dada a criação, em junho de 2005, do Colaboratório. Este grupo está ligado ao Núcleo de Gestão e tem o propósito de prestar assessoria e formação contábil aos empreendimentos e formadores.

Observa-se que cabe a esses formadores técnicos, em detrimento dos demais formadores da ITCP-USP, a detenção de conhecimentos contábeis. Juntamente com a Coordenação do projeto, os formadores técnicos dedicam-se a questões relacionadas à Autogestão, sendo os responsáveis pela execução da Contabilidade. O mesmo ocorre na prática dos grupos incubados, nos quais, em geral, os cooperados representantes da gestão dos empreendimentos, eleitos para os Conselhos Administrativo e Fiscal, se diferenciam dos demais por serem os únicos a se apropriarem da Contabilidade na condução dos negócios.

Dada a necessidade de se pautarem diversas questões relacionadas à Contabilidade na ITCP, o Colaboratório havia promovido, até agosto do ano de 2005, duas formações para os formadores, que apresentavam uma série de dificuldades e resistências com relação à Contabilidade. Tendo em mente essas barreiras, chegou-se a um consenso entre os membros do Colaboratório sobre a necessidade de se pensar em formas alternativas de abordar a Contabilidade com os formadores. Assim, passaram a ser pesquisados alguns métodos e a criar atividades e exercícios que apoiassem as intervenções em Contabilidade.

Foi então que se teve a ideia de experimentar o uso de métodos dramáticos no ensino da Contabilidade, afinal de contas, o teatro poderia ser um recurso didático muito útil, tanto para possibilitar a clarificação das situações abordadas quanto para permitir que houvesse um diálogo expressivo entre aqueles que ficaram responsáveis por ensinar e aqueles que ficaram incumbidos de aprender. 
A aplicação de uma oficina dramática de Contabilidade na ES seria, também, uma forma de se avaliar a interação prática dos pressupostos teóricos do TO e do RP. De modo geral, a oficina poderia certamente contribuir para (1) o aprendizado de jogos e técnicas teatrais que poderiam ser utilizados pelos formadores nas suas intervenções nos grupos; (2) a reflexão didática e a vivência prática dos papéis; (3) o entendimento e a busca de soluções para situações de opressão; e (4) a aprendizagem sobre a Autogestão a partir de sua simulação ou vivência dramática.

Em vez de se pautar em tal oficina algum tema circunscrito à Contabilidade, pensouse em uma condução flexível em termos de conteúdo, ou seja, que permitisse a manifestação dos participantes a respeito da Contabilidade. Dessa forma, na intervenção procurarse-ia estimular os sujeitos a dialogarem acerca das opressões percebidas por eles dentro do escopo da Contabilidade.

Era necessário, inicialmente, desvendar quais as opressões existentes na Economia Solidária relacionadas à Contabilidade, mais especificamente à Autogestão. Além disso, era preciso que se soubesse a quem caberiam os papéis de oprimido e opressor. Para isso, levantou-se uma discussão, antes da intervenção proposta, no Núcleo de Gestão, composto por formadores das chamadas áreas técnicas: Contabilidade, Direito, Economia, Administração, Engenharia de Produção e Ciências Sociais.

A pergunta a ser respondida por este grupo era: "O contador e a Contabilidade são opressores ou oprimidos?" Dada a presença de pessoas de outras áreas determinadas como técnicas na Incubadora, fora a Contabilidade, as respostas foram generalizadas a todas as áreas citadas anteriormente. Dois foram os principais argumentos, opostos entre si:

a) Nós, técnicos, somos oprimidos pelos formadores que, preconceituosamente, acham que nossas ciências são inúteis na ES, além de nos acusarem de burocratas e servidores do Capital; e

b) Nós, técnicos, somos opressores com relação aos formadores. Nossas áreas afastam os outros, seja pela linguagem que usamos, seja pelos setores e tipos de organização que atendemos majoritariamente.

Seriam essas as mesmas posições que seriam levantadas pelos formadores no dia da oficina quando perguntados sobre as opressões relacionadas à Contabilidade, mais especificamente à Autogestão? Para os formadores em geral, aqueles que cuidam das questões técnicas da gestão são oprimidos ou opressores? Da oficina, obtiveram-se respostas a essas perguntas, conforme será relatado adiante.

\subsection{Estrutura e desenvolvimento da oficina}

A seguir, está disposta a sequência de etapas da oficina e os seus respectivos objetivos:

1a Etapa: Apresentação dos objetivos da pesquisa e breve histórico do TO. 


\section{repec}

2a Etapa: Prática de exercícios e jogos teatrais que permitam: (a) explorar as possibilidades de movimentação, equilíbrio e toque; (b) aprimorar a percepção de sons e ritmos; (c) exercitar e desenvolver os sentidos sem o auxílio da visão; (d) comunicar-se através da imagem, usando a linguagem não verbal; e (e) despertar a memória, a emoção e a imaginação a partir da encenação de um relato.

Segundo Boal (2005b), é recomendável que se exercitem as categorias dos sentidos e da memória (2a Etapa) antes de se trabalhar mais especificamente com as simulações de opressão propriamente ditas. Isso se deve ao fato de que o conjunto do nosso corpo está excessivamente viciado com o cotidiano. É necessário, no trabalho teatral, reabilitar os sentidos e os músculos, libertando-os das especializações às quais o sujeito está submetido. 3a Etapa: Uso das seguintes técnicas do Teatro do Oprimido:

Teatro-Fórum (TF): Promover a interação público/plateia com o intuito de se estudarem conjuntamente as características da opressão em debate. Sendo assim, a partir do levantamento e da escolha de histórias de opressão vividas pelos formadores, preparam-se cenas em subgrupos que apresentem tais situações.

Um tempo aproximado de 30 minutos foi estimado para que os grupos elaborem as cenas, demarcando claramente os papéis de oprimido e opressor e evidenciando uma falha ou harmatia do oprimido (BOAL, 2005a), na medida em que ele não consiga solucionar a opressão (desafio que, posteriormente, é incumbido à plateia). Além dessas orientações, deve-se solicitar também que os participantes usem recursos estéticos em seus figurinos e cenários que traduzam a concepção que têm sobre o enredo representado. Fazer uso desses recursos é imprescindível em uma comunicação teatral (BOAL, 2005a), na medida em que eles trazem uma série de benefícios à intervenção ao facilitar a visualização das cenas e a transcendência do mundo concreto.

Teatro-Imagem (TI): Desenvolver a expressão teatral sem o uso da palavra falada. Terminada a fase de preparo das cenas, procede-se a um breve exercício de Teatro Imagem com o intuito de explorar a percepção expressiva dos grupos, ao se apresentarem e ao assistirem. A técnica do TI tem como propósito valorizar a estética do gesto, da cenografia e da caracterização dramática dos personagens, em detrimento da voz e da fala, meio expressivo mais utilizado e, muitas vezes, o único. Sendo assim, instrui-se que antes das apresentações, o grupo mostre suas cenas em seus respectivos cenários e com as ações e marcações que planejadas, porém, sem a utilização do recurso da fala. Ao público questiona-se, em seguida, sobre a compreensão dos elementos sugeridos pelas cenas corridas. Essas impressões iniciais são confrontadas com a apresentação plena das cenas.

Fórum: Apresentação dos grupos e intervenção da plateia que propõe soluções para as opressões levantadas.

4a Etapa: Avaliação (preenchimento de questionário).

Todos os exercícios e jogos aplicados estão devidamente explicados no livro Jogos para atores e não atores (Boal, 2005b). 


\section{repec}

\subsection{A vivência do Teatro Fórum e a troca de papéis}

Foi pedido aos participantes que relatassem situações de opressão que haviam vivido no seu trabalho na Incubadora, relacionadas à Autogestão e à Contabilidade. Dentre as situações apresentadas, escolheu-se para ser encenado o relato de um formador que disse que se sentiu oprimido pela Coordenação da ITCP-USP quando ficou sabendo que, nessa instância, resolveu-se contratar uma pessoa temporária para cobrir a ausência da secretária do projeto, afastada por motivos de saúde.

O caso da contratação do secretário substituto temporário da secretária efetiva do projeto e a sua repercussão constituíam a questão em voga na ITCP quando da intervenção dramática: a quem compete a Autogestão? Duas eram as possíveis respostas: (a) àqueles que representam o coletivo, ou seja, os que assumem o papel de Coordenação, esta, por sua vez, tendo seu trabalho associado às ciências técnicas, econômicas e burocráticas, onde se insere a Contabilidade; e (b) ao próprio coletivo. Segundo o relato inicial do formador que teve sua história escolhida, a Autogestão e a Contabilidade, que deveriam ser coletivas, estavam concentradas na Coordenação. Aos opositores cabia o argumento de que a Coordenação tinha muitas tarefas. Os dois grupos pareciam concordar que a Coordenação, apoiada pelos formadores das áreas técnicas, conduzia a gestão do projeto.

Tinha-se ali uma grande oportunidade para trabalhar conjuntamente com o TF e TI (dentro da proposta do TO) e a vivência e troca de papéis (dentro da proposta do RP), considerando-se os papéis levantados (coordenação e formadores em geral) e as supostas opressões exercidas transitivamente entre eles, de acordo com os dois grupos. Realizouse, então, o fórum, com a apresentação das cenas, sucedidas de intervenções da plateia. A seguir, são descritas resumidamente algumas das cenas e intervenções:

- Grupo 1: Formadores (oprimidos) Vs. Coordenação (opressora)

Este grupo apresentou duas cenas. A primeira consistiu em um diálogo entre um formador novo, que com "sede de descoberta", pergunta tudo sobre o novo trabalho na ITCP a uma formadora representante da Coordenação. Ao perguntar sobre o funcionamento dos contratos daqueles que trabalham no projeto e ao se referir especificamente ao contrato da secretária (que é diferenciado, de autônomo), ao novato recomenda-se que "não volte a tocar no assunto porque é polêmico". Na segunda cena, mostra-se mais um exemplo em que um formador é oprimido pela coordenação, porém, agora se trata do caso inicialmente levantado: a contratação temporária de um secretário. $\mathrm{Na}$ cena, trava-se um diálogo, aos cochichos, entre dois formadores sobre o novo secretário, em que um explica ao outro quem é o sujeito e como tinha chegado lá. Ambos se mostraram indignados por não terem sido consultados.

- Grupo 2: Coordenação (oprimida) Vs. Formadores (opressores)

O segundo grupo quis mostrar em suas cenas que o trabalho autogestionário 
não significa trabalho sem burocracia, sem responsabilidade e sem esforço. Isso se deu por meio de vários e cômicos exemplos de situações em que os formadores saem "de fininho" e a Coordenação acaba ficando sobrecarregada.

\subsection{Análise da oficina}

Apesar de poucos terem sido os elementos estéticos utilizados nas apresentações e da prioridade dada à fala ao invés da ação, percebeu-se que os formadores sentiram-se à vontade para desempenharem seus papéis, mostrando-se, também, interessados em uma discussão aprofundada sobre as relações de opressão, em geral, e também especificamente na Autogestão e na ITCP. Algumas pessoas interpretaram os dois lados da opressão: formadores e coordenadores, como opressores e oprimidos. Na primeira cena do Grupo 1, a pessoa que havia relatado a opressão como oprimida fez o papel de opressora, o que foi, segundo ela, um tanto fácil, já que sabia detalhadamente de como havia se desenrolado a situação na vida real e, consequentemente, se lembrava claramente da postura e dos argumentos do seu opressor.

No dia da oficina, as coordenadoras do projeto não estavam presentes, porém contou-se com a presença de outros membros da Coordenação: os "subcoordenadores" (representantes de Gepems e Núcleos). Duas foram as implicações observadas em decorrência da ausência das coordenadoras: houve facilidade de se abordar, pelos formadores, o assunto mal resolvido da contratação do secretário temporário; e os coordenadores de área tomaram a posição de defesa da Coordenação da ITCP.

Outra observação importante é que a maioria dos integrantes do Núcleo de Gestão (grupo da ITCP representante das áreas técnicas) escolheu participar do Grupo 2, no qual a Coordenação era tida como oprimida, reforçando-se assim o apoio das áreas técnicas a este órgão da ITCP. De fato, à Coordenação cabem as responsabilidades administrativas e contábeis do projeto, sendo que aos formadores recaem apenas as atividades de incubação e formação dos grupos. Percebeu-se que o enfrentamento das situações de opressão do Grupo 2 mostrou-se mais efetivo, afinal de contas, sendo opressora ou oprimida, a Coordenação por si só parece ter mais poder que o formador individual. Note-se que a subordinação da Coordenação é ao coletivo (Conselho de Formadores), não a um ou outro formador. Sendo assim, a coordenadora como oprimida consegue mais facilmente resolver a opressão do que o formador oprimido.

Ambos os grupos apresentaram-se em diferentes salas, porém, dentro do espaço da ITCP, ou seja, executaram o fórum dentro de seu próprio local de trabalho, sendo que o Grupo 1 (defensor dos formadores) se apresentou na sala de Conselho coletivo e o Grupo 2 (defensor da Coordenação) se apresentou na sala da Coordenação. Os efeitos da reutilização do espaço de trabalho para a criação teatral, que no caso simula eventos do próprio trabalho, contribuem significativamente no desenvolvimento de uma análise do cotidiano, que, como se verificou, está permeado de conflitos e opressões. 
Uma dúvida frequente entre os participantes refere-se ao movimento de libertação do oprimido. Quando e como ocorre? A resposta que se chegou para discussão foi a de que a libertação não cabe exclusivamente ao oprimido, mas também à mudança do opressor, sendo que a quantidade de oprimidos unidos também contribui na superação da opressão.

De fato, não houve uma finalização concreta da oficina: as pessoas foram saindo aos poucos; assim como não houve um início exato: as pessoas foram chegando uma a uma e se integrando nas atividades. O que se observou neste momento final foi a confusão entre a ficção e a realidade. Ora as pessoas falavam por elas, ora falavam por seus personagens. $\mathrm{O}$ jogo do teatro permanece, agora, cada vez mais indissociado da vida.

\section{CONCLUSÕES}

As opressões relacionadas à Contabilidade, mais especificamente à Autogestão, levantadas e encenadas na ITCP-USP, referem-se à condição técnica desta ciência. Verificouse que, do ponto de vista de suas atividades e responsabilidades, a Contabilidade afasta os formadores, que se veem oprimidos em relação a essas atribuições. Esse afastamento, por sua vez, faz com que a Coordenação se sinta oprimida, dada a quantidade de tarefas que é obrigada a cumprir. Considera-se, sob essas circunstâncias, a vontade geral da coletivização da Autogestão e a concentração da "Autoburocratização" das questões técnicas do projeto (nas quais se insere a Contabilidade) nas mãos da Coordenação da ITCP-USP. Por outro lado, a Coordenação pareceu concentrar, também, informações e decisões que caberiam ao coletivo, representando-se, assim, como opressora com relação aos formadores, do ponto de vista da Autogestão.

De maneira geral, as empresas inseridas na economia capitalista concentram as atividades contábeis e administrativas em cargos e funções que se ligam diretamente aos mais altos níveis hierárquicos, deixando os funcionários à parte deste processo. Com este estudo, verificou-se que mesmo em um projeto em que se propõe a gestão coletiva, esta é concentrada nas mãos de uma coordenação, à maneira das empresas capitalistas, ficando os formadores também alheios à Contabilidade e à tomada de decisão de fato.

A aplicação do Teatro do Oprimido facilitou o diálogo entre as partes, levando-se ao esclarecimento de situações conflituosas, à compreensão dos diferentes pontos de vista a respeito das funções e organização da gestão do projeto e também ao maior enfrentamento daquelas questões que os participantes consideravam como opressão. A troca de papéis, sustentada pelo método do RP, por sua vez, apoiou a realização do fórum e possibilitou àqueles que intervieram em cena, nas diferentes posições de opressão, uma experimentação de combinações de papéis (Coordenação/formador e oprimido/opressor). Sendo assim, considera-se que a aplicação conjunta dos métodos RP e TO foi favorável à vivência de situações relacionadas à Autogestão e à Contabilidade no movimento de Economia Solidária. 
Constataram-se, pela experimentação dos métodos dramáticos sugeridos (RP e TO), características do relacionamento dos papéis da Coordenação e formadores que sugerem a existência de uma relação de opressão no que se refere à concentração da gestão. Observa-se que a opressão evidenciada assemelha-se não só àquela encontrada entre patrão e funcionário da empresa capitalista, mas também à opressão existente entre aqueles que detêm o conhecimento e aqueles que são alheios ao mesmo, sendo que, no caso, tratou-se dos conhecimentos contábil e administrativo. Dessa forma, a opressão por função associase à opressão do porte do conhecimento, esta por sua vez é encontrada tanto na relação professor/aluno (sendo aquele o sujeito ativo que conduz o processo ensino-aprendizagem deste) quanto na relação contador/não contador (sendo aquele o guardião do conhecimento contábil ao qual este está subordinado).

Considera-se que, ao adotarem técnicas de dramatização, como as utilizadas nesta pesquisa, os formadores da ITCP poderiam obter resultados semelhantes com os empreendimentos que acompanham, enriquecendo a discussão sobre Autogestão e Contabilidade por meio de experimentação dos pontos de vista dos integrantes dos grupos incubados, em vez da simples discussão das ideias.

A aplicação do TO e RP em cursos de Ensino Superior de Ciências Contábeis também é recomendável para que se transforme o ato pedagógico de mera exposição para ação dramática, a qual pode contribuir para a representação viva do real, possibilitando, assim, uma visão mais crítica dos conceitos.

\section{REFERÊNCIAS}

BOAL, A. Teatro Legislativo: Versão Beta. Rio de Janeiro: Civilização Brasileira, 1996.

Teatro do Oprimido e Outras Poéticas Políticas. 7. ed. Rio de Janeiro: Civilização Brasileira, 2005a.

Jogos para atores e não-atores. 8. ed. Rio de Janeiro: Civilização Brasileira, 2005b.

CARVALHO, José L. F. dos Santos de, CARVALHO, Frederico A. Azevedo de. Atores e Papéis no Ensino da Administração: Estudo de Caso em uma Empresa Júnior. In: ENCONTRO ANUAL DA ANPAD, 28., 2004, Curitiba. Anais... Curitiba: Associação Nacional dos Cursos de Pós-Graduação em Administração, 2004.

CRAIG, Russell; AMERNIC, Joel. Roleplaying in a Conflict Resolution Setting: Description and Some Implications for Accounting. Issues in Accounting Education. Vol. 9, n. 1, p.28-44. Spring, 1994. 
CRUMBLEY, D. Larry; SMITH, Katherine T.; SMITH, L. Murphy. Educational novels and student role-playing: a teaching note. Accounting Education. Vol. 7, n. 2, p.183-191, 1998.

FREIRE, Paulo. Pedagogia do oprimido. 31. a ed. Rio de Janeiro, Paz e Terra, 2001.

HASKINS, Mark E.; CRUM, Robert P. Cost Allocations: A Classroom Role-Play in Managerial Behavior and Accounting Choices. Issues in Accounting Education. p.109-130, 1985.

HAYES, David C.; REYNOLDS, J. Kenneth. Caroline`s Candy Shop: An In-Class Role-Play of the Revenue Cycle. Journal of Information Systems. Vol. 19, n. 1, p.131-154. Spring, 2005.

KRASILCHIK, Myriam. Prática de Ensino de Biologia. 3. ed. São Paulo: Harbra, 1996.

MARCONI, Marina de Andrade; LAKATOS, Eva Maria. Fundamentos de Metodologia Científica. 5. ed. São Paulo: Atlas, 2003.

MARION, José Carlos. O ensino da contabilidade. 2. ed. São Paulo: Atlas, 2001.

NAFFAH, N. A. Psicodrama: descolonizando o imaginário um ensaio sobre J. L. Moreno. São Paulo: Brasiliense, 1979.

NÉRICl, Imidio Giuseppe. Metodologia do Ensino, uma Introdução. 3. ed. São Paulo: Atlas, 1989.

PELEIAS, Ivam Ricardo (Org.). Didática do Ensino da Contabilidade - Aplicável a outros Cursos Superiores. São Paulo: Saraiva, 2006.

RUAS, Roberto R. Literatura, Dramatização e Ensino em Administração - uma Experiência de Apropriação de Práticas Teatrais à Formação Gerencial. In: ENCONTRO ANUAL DA ANPAD, 28, 2004, Curitiba. Anais... Curitiba: Associação Nacional dos Cursos de PósGraduação em Administração, 2004.

SWINK, David F. Role-play your way to learning. Training \& Development. Vol. 47, n. 5, p.91-97. May, 1993.

TEIXEIRA, Tânia Márcia Baraúna. Dimensões Sócio Educativas do Teatro do Oprimido de Augusto Boal. Revista Recrearte. Espanha: [s.n.], v. 4, 2005. 